\title{
Retrofitting rooftops to support multiple Green Infrastructure systems
}

\author{
J. Drake ${ }^{1}$, L. Margolis ${ }^{2}$ B. Sleep ${ }^{3}$ and G. Mishriki ${ }^{4}$ \\ ${ }^{1}$ Assisant Professor, Department of Civil Engineering and John H. Daniels Faculty of \\ Architecture, Landscape and Design, University of Toronto, 35 St. George St., Toronto, ON, \\ M5S 1A4; PH (416) 978-8248; e-mail: jenn.drake@ utoronto.ca \\ ${ }^{2}$ Assistant Professor, John H. Daniels Faculty of Architecture, Landscape and Design, University \\ of Toronto, 230 College St., Toronto, ON, M5T 1R2; PH (416) 946-5478; e-mail: \\ liat.margolis@daniels.utoronto.ca \\ ${ }^{3}$ Professor and Chair for the Department of Civil Engineering, University of Toronto, 35 St. \\ George St., Toronto, ON, M5S 1A4; PH (416) 978-3005; e-mail: sleep@ecf.utoronto.ca \\ ${ }^{4}$ Director of Engineering, Sky Solar (Canada) Ltd., 100 Leek Crescent, Unit 12, Richmond Hill, \\ ON, L4B 3E6; PH (905) 889-9188; FAX (905) 889-0006; e-mail: \\ george.mishriki@skysolargroup.com
}

\begin{abstract}
The second phase of the University of Toronto's Daniels Faculty of Architecture, Landscape and Design Green Roof Innovation Testing Laborarty (GRITlab) officially opened in 2014. The GRITlab project is an interdisciplinary research facility which brings together engineering, architecture and biology researcher. Phase II of GRITlab involved the retrofitting of the Daniels 106-year old roof to allow for the construction of two full-scale integrated green and photovoltaic systems. The completed GRITlab will serve as a research, educational and demonstration facility for green infrastructure. This paper will present the planning, design and construction of GRITlab Phase II and discuss the challenges of retrofitting rooftops to support green infrastructure.
\end{abstract}

\section{INTRODUCTION}

Throughout Canada manufacturers and distributers of green roof and photovoltaic (PV) panels compete for installation of projects on industrial, commercial and high-density residential rooftops. These technologies are often viewed as direct competitors as both systems reduce the environmental impact of buildings, albeit through different mechanisms. Consequently, rooftop designs rarely, if ever, apply both technologies. However, when integrated, green roofs systems may improve the performance and lifetime of PV arrays, while also reducing effluent runoff during storm events. Reducing the operating temperature of PV panels increases their conversion efficiency. Furthermore, lowering operating temperatures reduces PV panel degradation rates and thus increases their useful lifetime. Green roofs may produce cooler surface temperature than white roofs due to evapotranspirative cooling. 
In 2014, an integrated green roof-solar photovoltaic (GR-PV) system was constructed on top of the Daniels Building at the University of Toronto. The new roof system is the first of its kind in Ontario and is a part of the expanded Green Roof Innovation Testing Laboratory (GRITlab) at UofT. The design of GR-PV system required archival research and structural analysis of the existing roof, which is over 100 years old, in order to support the weight of the new green infrastructure. Through the design process structural, operational, and research-drive constraints were balanced. Fully constructed the GRITlab research is now underway.

The GRITlab project is a truly multi-disciplinary research effort which comprises undergraduate and graduate students from civil engineering, landscape architecture, biology and mechanical engineering. The two-year planning process for the GRITlab expansion involved extensive collaboration between researchers, university services, engineering consultants and product suppliers. This paper will present the motivations for the adoption of integrated GR-PV systems within the Greater Toronto Area as well as the engineering and experimental design of the GRITlab expansion. Lessons learned from planning, design and construction experiences, challenges and successes will be discussed.

\section{PROJECT BACKGROUND}

\section{GRIT LAB Phase I}

Conventional rooftops may not only divert up to $100 \%$ of stormwater and increase downstream erosion (Mentens et al., 2006), but also account for up to $60 \%$ of building cooling load, greatly increasing building energy consumption for cooling in warm weather (Maneewan et al., 2005). GR address both of these issues; GR capture and evapotranspire stormwater, and evapotranspiration and changes in albedo associated with vegetation contribute to roof cooling and decreased energy use for cooling (Oberndorfer et al., 2007).

Phase I of the GRITlab includes thirty-three meso-scale green roof modules constructed on the roof of the Daniels Faculty Building at the University of Toronto. Through Phase I researchers are examining the influence of design and maintenance on green roof resilience, biodiversity and functionality. Phase I experimental parameters included substrate depth $(10 \mathrm{~cm}$ or $15 \mathrm{~cm}$ ), substrate type (FLL or organic), plant mix (Sedum or grass/forb) and irrigation (none, timed, or moisture sensor). Phase I researchers have demonstrated that two years after planting vegetation cover and above ground biomass is significantly less when industry-standard FLLbased growing media is specified (MacIvor et al., 2013). Grass and forb diversity is dependent on supplemental irrigation (MacIvor et al., 2013). Results from Phase I are intended to be used to augment the Toronto Green Roof Construction Standards (2010) and to develop design tools for the Canadian green roof industry (Figure 1). Each module is outfitted with a tipping bucket gauges (to measure outflows), a soil moisture sensor, and five thermistors arranged in a vertical profile (to measure evaporative cooling). 


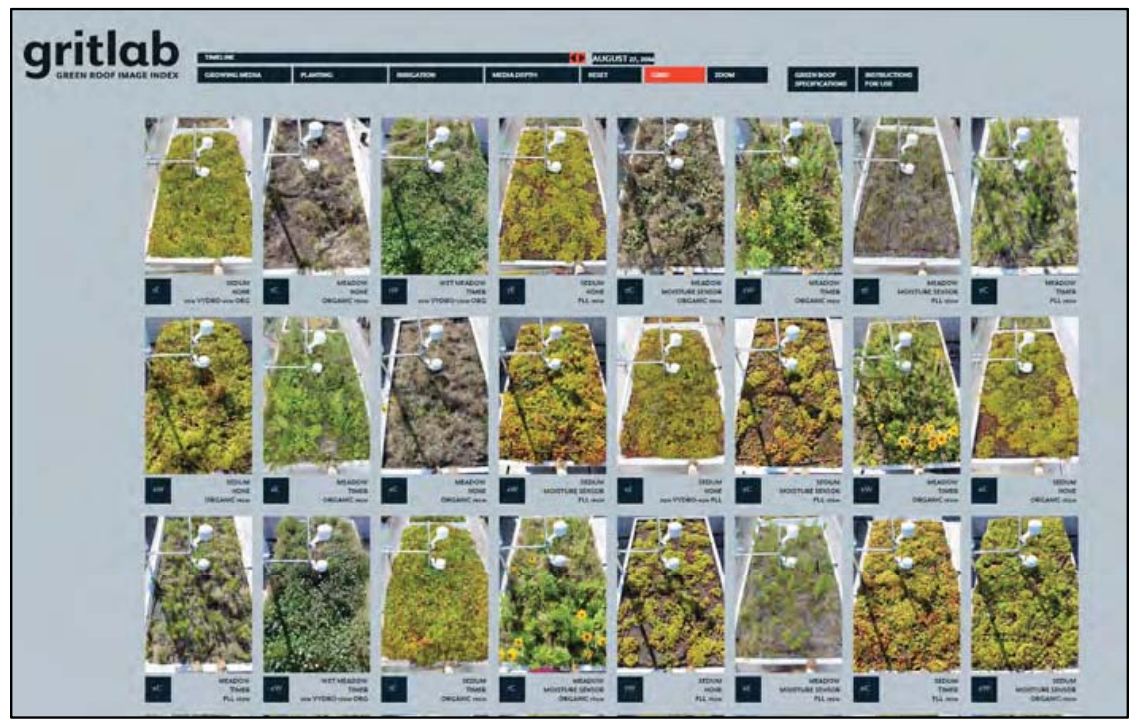

Figure 1: Example of a web-based application Imaging Tool produced through Phase 1 Research (Gritlab Green Roof Image Index, 2014).

GRIT LAB Phase II

PV panels erected on rooftops generate renewable energy reducing the demand for fossil fuels. Electricity produced by PV panels can supplement electricity supplied from the wider energy distribution system reducing demand during peak usage hours and generating saving in building energy costs. Reducing the operating temperature of PV panels increases the conversion efficiency of PV panels by as much as $0.5 \%$ per ${ }^{\circ} \mathrm{C}$ (Krauter et al., 1999). The relationship between temperature and energy production is not linear. PV panels operate most efficiently under cold and sunny conditions. Lowering operating temperatures has also been shown to minimize the long-term degradation of PV panels (King et al., 2000). Chemisana and Lamnatou (2014) positive synergic effects including increased energy output and decreased soil temperatures from small scale testing of integrated GR-PV systems in Spain. Phase II of the GRITlab aims to demonstrate and study integrated GR-PV systems. Phase II includes four PV arrays comprised of 40 280W MEMC panels with a total DC capacity of $11.2 \mathrm{~kW}$ provided by Sky Solar and Schletter Racking (Figure 2). Half of the PV arrays are underlain by two full-scale modular green roof system provided by Bioroof Systems and half are underlain by a white (high reflective) roof membrane (control). The green roofs are constructed at two and four feet below the PV array and seeded with sixteen grass and forb species native to Southern Ontario. Growing media properties are summarized in Table 1. 
Table 1: Growing Media Properties

\begin{tabular}{|c|l|c|}
\hline Standard & \multicolumn{1}{|c|}{ Property } & Bioroof Eco-blend \\
\hline \multirow{2}{*}{$\begin{array}{c}\text { Porosity } \\
\text { ASTM E2399) }\end{array}$} & Pore volume & $>60 \%$ \\
\cline { 2 - 3 } & Air filled porosity & $>10 \%$ \\
\cline { 2 - 3 } $\begin{array}{c}\text { Moisture } \\
\text { (ASTM E2399) }\end{array}$ & Saturated hydraulic conductivity & $>0.01 \mathrm{~cm} / \mathrm{s}$ \\
\hline $\begin{array}{c}\text { Density (ASTM } \\
\text { E2399) }\end{array}$ & Max media density at saturation & $>60 \%$ \\
\cline { 2 - 3 } & Dry density & $1.10 \mathrm{~g} / \mathrm{cm}^{3}$ \\
\hline
\end{tabular}

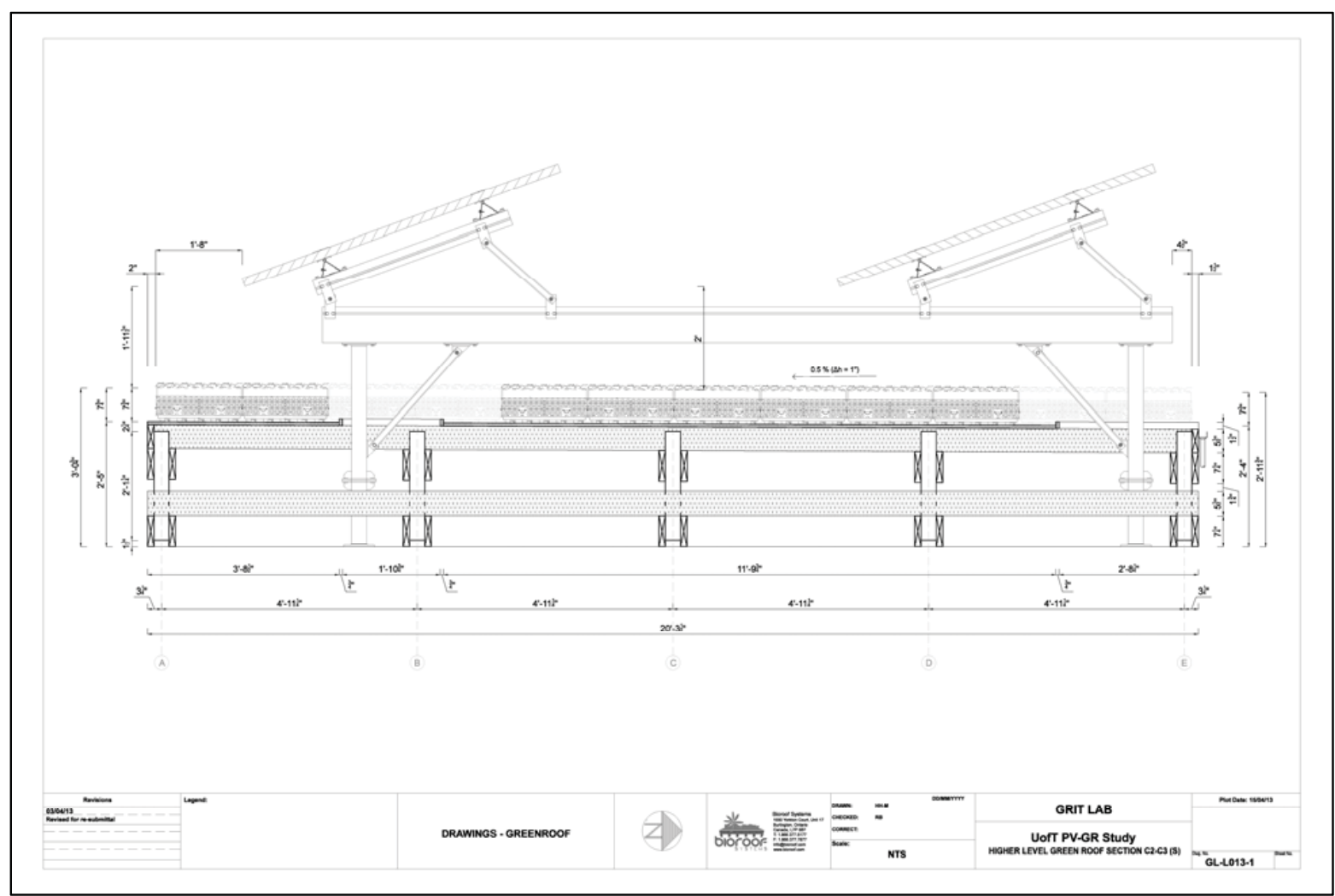

Figure 2: GRITlab Phase II Design Drawings provided by Schletter Racking and Bioroof Systems Inc.

Research objectives of Phase II include:

- Creation of customized architectural graphic standards for landscape architectural design of GR-PV systems.

- Assessment of the effect of evaporative cooling on PV temperature and energy production. 
- Investigation of the relationship between water balance (precipitation, evapotranspiration and runoff) and plant growth.

- Investigation green roof stormwater management and irrigation requirements in relation to climatic conditions.

- Assessment of the effect of PV panel height from green and white roof surfaces on PV temperature and energy production.

- Assessment of PV panel induced variables (shading, water shedding and wind scouring) on plant growth.

- Development of draft standards for design and construction and draft protocols for operation and maintenance of integrated GR-PV systems.

Design and construction of monitoring and data acquisition systems is currently underway. Storm flows, soil moisture potential, wind speed, solar irradiance and solar panels, soil and atmospheric temperatures will be continuously monitored over the next three years.

\section{PLANNING, DESIGN AND CONSTRUCTION}

\section{Structural Considerations}

The Daniels Faculty building was constructed in 1908 and was first used as the Royal College of Dental Surgeons (Figure 3). Original as-built structural and architectural drawings were located through the University of Toronto Archives (Figure 3). The Daniels Faculty building is composed of a structural steel system with concrete foundations. Local cuts were conducted in the existing ceiling and roof to accurately assess the acting dead loads and verify the as-built drawings.

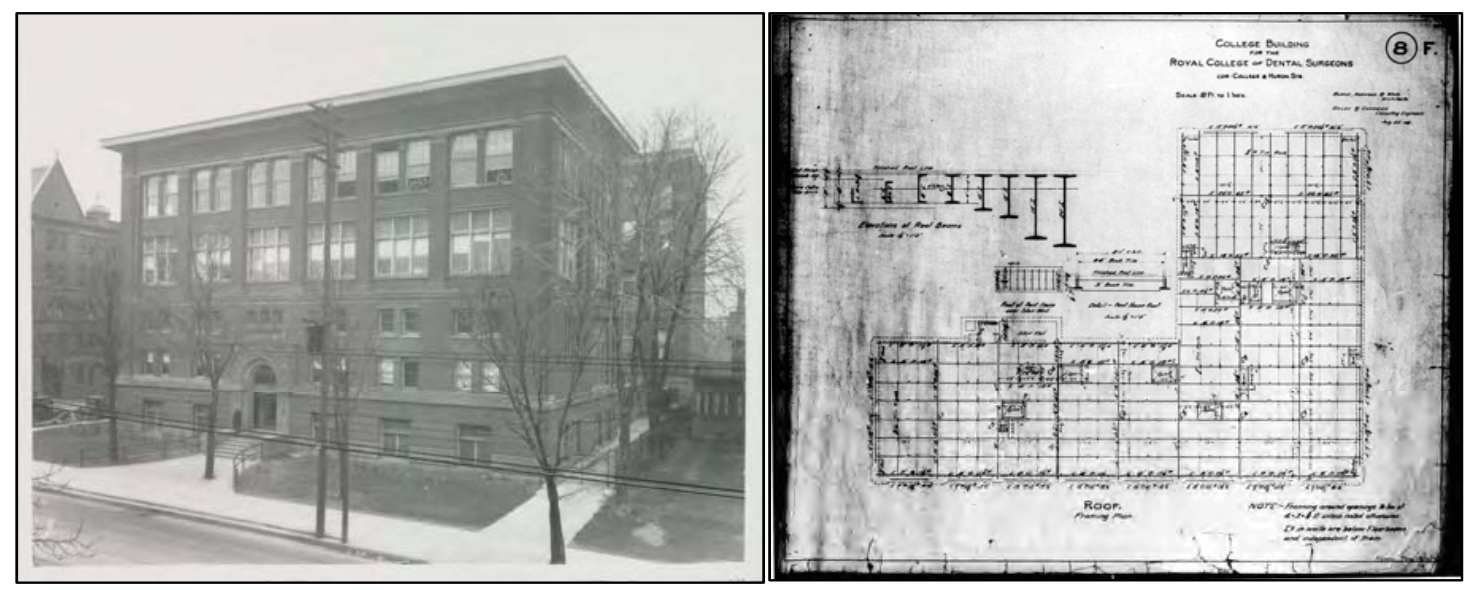

Figure 3: Royal College of Dental Surgeons: Photo from 1923 (left), Original 1908 As-Built drawings (University of Toronto Archives). 
The vertical supports of the raking frames were designed to be centred and site welded to the top flanges of the existing main steel girders supporting the roof structure. Structural analysis and design was performed with Sap2000. Construction was completed in August 2014 and was sequenced as follows:

1. Materials were crane lifted onto the roof.

2. The roof was excavated down to the steel structure in specific locations.

3. The racking vertical members were welded to the steel structure.

4. Roof excavations were repaired and a white roofing membrane was applied.

5. The remaining photovoltaic racking frames were assembled.

6. Wooden decking was assembled.

7. Application of roofing membrane and flashing on wooden decking.

8. Installation of the solar panels.

9. Assembly and installation of green roof modules.

10. Installation of green roof soil, irrigation system and seeding.

\section{Research Considerations}

In order to address research objectives for Phase II outflows from the GR-PV systems must be measureable and the two modules needed to be as comparable as possible. A custom Schletter elevated racking system was designed to accommodate for the slope of the existing structural steel frame. Raised wood decks were built to elevate the green roof and to allow for space for hydrologic instrumentation (Figure 4). The south edge on each green included a drip line to allow for the future construction of a stormwater collection system. Additionally, both green roof decks were sealed with impermeable roofing membranes and edge flashing.

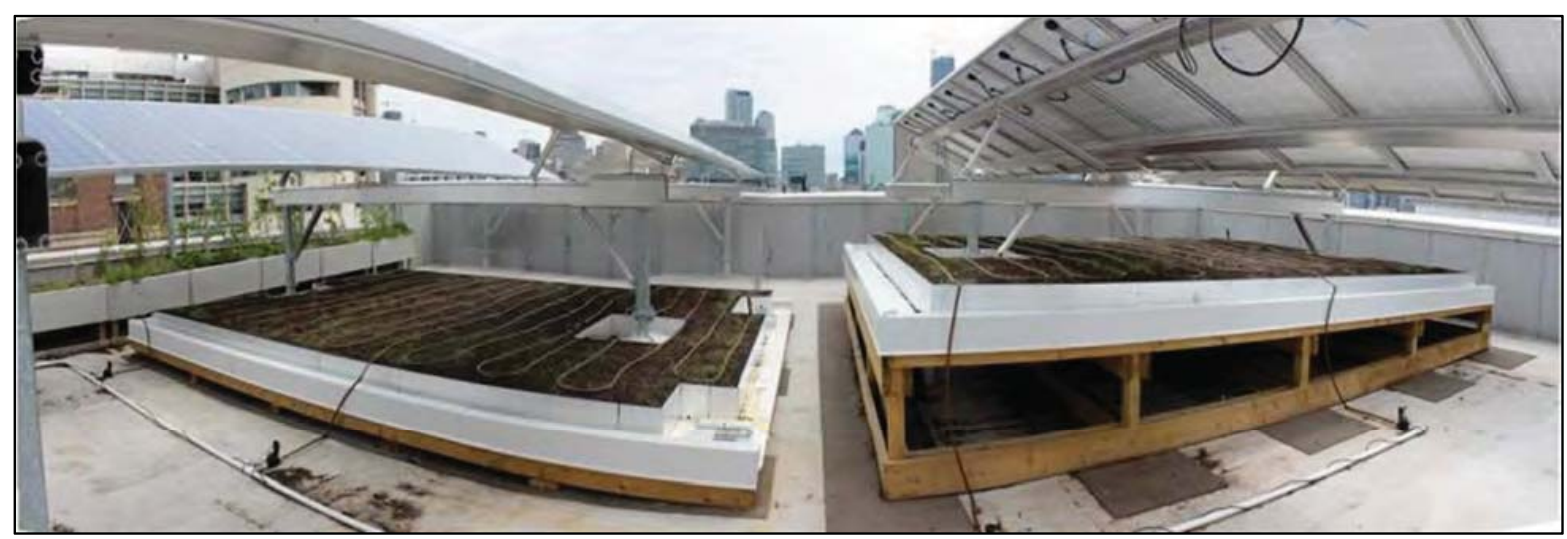

Figure 4: Completed Phase II GRITlab. 


\section{STUDENT INVOLVEMENT}

GRITlab functions as an educational and research facility (Figure 5). When fully operational, Phase II will be managed by landscape architecture graduate students and support several engineering Masters and $\mathrm{PhD}$ theses. Undergraduate research projects are supported through summer research scholarships. International students have also joined the GRITlab team through internship and exchange programs such as Science without Borders. Through their involvement with the GRITlab students acquire multiple skills relevant to the design, construction and operation of green roofs, PV panels and irrigation systems including: data collection techniques, operation and maintenance of components of the integrated GR-PV system, architectural graphic standard details, statistical analysis of data, modelling of hydrologic and energy systems, and the development of design and construction guidelines. The students will learn to critically evaluate previous presented results, work in a multidisciplinary team, interact with industry partners and experts, present technical material to mixed audiences, prepare journals, technical reports and architectural drawings, and manage project budgets and schedules.

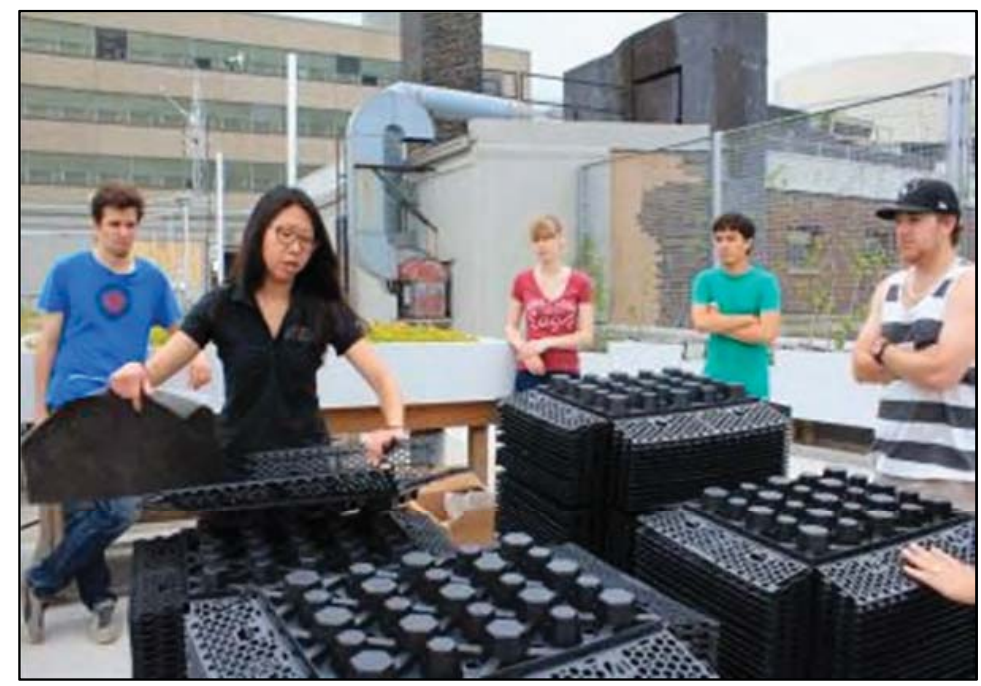

Figure 5: Student training by industry partner Bioroof Systems on green roof module assembly

\section{CHALLENGES AND SUCCESSES}

The two main challenges of this project include the retrofit of an existing 100-year old building rooftop, and the permitting process for a combined GR-PV system as detailed below:

Retrofit:

- Existing steel framing consists of steel grades and construction techniques that date back to 1908 and that are no longer used today. 
- As-built drawings were missing some information and therefore required a physical on-site survey to verify exact steel section sizes, grades, acting dead loads, locations and elevations.

- Design and fabrication of custom racking system was needed to accommodate the variable slopes of the top levels for the existing structural skeleton of the roof.

- As per the conducted structural verification, only the existing main steel girders have proved to having reserve of structural capacity for the additional loads of the racking system. Therefore, the vertical supports of the adopted racking system had to be site welded to the top flanges of the existing main steel girders. In new build scenarios, PV racking systems are ballasted, and therefore simpler and less costly.

- Roof membrane repair had to follow the welding immediately as to not void the roofing warrantee. To accommodate for inclement weather, temporary boxes had to be constructed to protect the excavated areas.

- Craning and construction had to take into consideration the safety of students and faculty occupying the building.

Permitting process:

- The building permit process was relatively lengthy because this was the first time for the building department at city of Toronto to review a building permit for a combined GR-PV system.

The collaboration with a number of manufacturers and suppliers, as well as with the university management and administration was key to the success of this project for three reasons:

1. Professional expertise and liability was necessary to meet the technical and legal requirements of the installation. For example, the added structural load of the proposed GR-PV infrastructure required an engineer of record to conduct the analysis and design and assume liability. Sky Solar's structural engineer conducted the physical investigation, the design of the solar racking in collaboration with the engineering team at Schletter Racking, and the structural analysis using specialized software (SAP2000). Sky Solar then issued stamped drawings for the University approvals and City permitting processes. Following the structural analysis, a licensed engineer at IRC Building Group led the permitting efforts and assumed liability for the permit application, which also included details drawings of the green roof provided by Bioroof Systems. Expert solar constructor TerraGen Solar executed the welding and assembly of the solar racking. Expert roofers Sempler Gooder facilitated roof excavation and repair to meet the requirements of warrantee holder, Siplast. And finally, DH Water Management configured the irrigation manifold and control system. 
2. The partnership with industry allowed for research students to observe the construction sequence, and take part in the assembly of various components. The students had the opportunity to gain practical experience and to better understand the complexity of constructing green infrastructure.

3. Support by the University Facilities \& Services (F\&S) for this research initiative was crucial in terms of logistics. Since the project involved ten different contractors, F\&S facilitated a general constructor to manage and insure the project and individual parties during construction. F\&S also ensured safety in and around the site by notifying various building occupants and maintenance crews. Their team has and continues to provide support with regards to building infrastructure including water, electricity, access and safety.

\section{CONCLUSION}

There are many barriers (cost, permitting, time, etc.) which prevent the inclusion of green infrastructure in retrofit projects. The management of urban water systems is directly tied to energy consumption and long-term environmental impacts. Installing PV panels over a GR provides shading and protection from the environment. Roofing and solar energy industries are interested in mixed-use systems but there are many questions regarding constructability and design. Through the construction of GRITlab Phase II project stakeholders collaborated to address both the structural constraints and research objectives of the lab. Through this project industrial and academic collaborators have gained unique professional experience regarding designing, planning and constructing integrated GR/PV systems. Such roof systems do not yet exist commercially, and research efforts over the coming years will examine interactions, such as the shading of GR, water shedding off PV panels, the height of PV panels and localized wind patterns induced by the PV panels, that are not yet understood.

\section{AKNOWLEDGEMENTS}

Funding for this project is provided by Natural Sciences and Engineering Research Council of Canada (NSERC) Strategic Partnership grant in collaboration with industry partners, Sky Solar, Bioroof Systems, IRC Building Science Group, and DH Water Management. Additional support is provided by: Schletter, Semple Gooder Roofing Corporation, Siplast, TerraGen Solar, Tremco Roofing, University of Toronto Facilities \& Services, and the Daniels Faculty.

\section{REFERENCES}

Chemisana, D. and Lamnatou, C. (2014). Photovoltaic-green roofs: An experimental evaluation of system performance. Applied Energy, 119(2014): 246-256. 
Gritlab Green Roof Image Index (2014).

http://grit.daniels.utoronto.ca/green_roof_image_index/\#

King D., Kratochvil J., and Boyson W. (2000). Stabilization and performance characteristics of commercial amorphous-silicon PV modules. Photovoltaic Specialists Conference, 2000. Conference Record of the Twenty-Eighth IEEE, 1446-1449.

Krauter, S., Araujo, R. G., Schroer, S., Hanitsch, R., Salhi, M. J., Triebel, C., and Lemoine, R. (1999). Combined photovoltaic and solar thermal systems for façade integration and building insulation, Solar Energy, 67(4-6): 239-248.

MacIvor, J.S., Margolis, L., Puncher, C.L., Carver Matthews, B.J. (2013). Decoupling factors affecting plant diversity and cover on extensive green roofs. Journal of Environmental Management, 130: 297-305.

Maneewan S., Hirunlabh J., Khedari J., Zaghmati B., and Teefasap S. (2005). Heat gain reduction by means of thermoelectric roof solar collector. Solar Energy, 78(4): 495-503.

Mentens J., Raes D., and Hermy M. (2006). Green roofs as a tool for solving the rainwater runoff problem in the urbanized 21st century? Landscape and Urban Planning, 77(3): 217-226.

Oberndorfer E., Lundholm J., Bass B., Coffman R., Doshi H., Dunnett N., Gaffin S., Kohler M., Liu, K., Rowe B. (2007). Green roofs as urban ecosystems: Ecological structures, functions, and services. Bioscience, 57(10): 823-833.

Toronto Green Roof Construction Standards (2010). http://www1.toronto.ca/wps/portal/contentonly?vgnextoid=77420621f3161410VgnVCM 10000071d60f89RCRD

University of Toronto Archives. (1908). Physical Plant Department Fonds. Aperture cards A1988-0039, building 28, C-17-16.

University of Toronto Archives. (1923). Dept. of University Extension and Publicity Fonds. A65-0004/037(03) 